\title{
Gerenciamento de riscos físicos em ambiente fabril de calçados
}

Daniel Ferreira Fernandes de Albuquerque

daniel.albuquerque@ee.ufcg.edu.br Universidade Federal de Campina Grande (UFCG), Campina Grande, Paraiba, Brasil

Jailson Alves da Nóbrega

jailson.nobrega@ifce.edu.b

Instituto Federal de educação, ciência e

(tocnologia do Ceará (IFCE), Tabuleiro do

Norte, Ceará, Brasil

Raphael Henrique Falcão de Melo raphael.melo@ifpb.edu.br

Instituto Federal de educação, ciência e ecnologia da Paraíba (IFPB), Cajazeiras, Paraíba, Brasil

\section{César Araújo Pires}

esar.pires@ee.ufcg.edu.b

Universidade Federal de Campina Grande (UFCG), Campina Grande, Paraíba, Brasil

\author{
RESUMO
}

Acidentes de trabalho e problemas de saúde ocupacional são constantes em diversos segmentos industriais. No entanto, estes indesejáveis problemas podem ser mitigados ou extintos quando se tem um cuidadoso projeto de reconhecimento e eliminação dos potencias agentes físicos, químicos e biológicos que levam riscos à integridade e saúde dos trabalhadores. O presente estudo tem por objetivo utilizar ferramenteas de gerenciamento de risco para avaliar os riscos físicos, propondo as devidas soluções em ambiente de trabalho de uma micro indústria calçadista situada na cidade de Campina Grande-PB. Para o desenvolvimento de tal, tiveram-se como base as normas regulamentadoras vigentes. A metodologia usada consistiu de pesquisa em campo e análise da exposição dos trabalhadores aos riscos eminentemente físicos. As soluções sugeridas garantem o cumprimento dos requisitos normativos, as quais tendenciam para a redução dos ruídos sonoros, a obtenção do conforto térmico mínimo, o aumento da iluminância interna e a operação segura do maquinário. Conclui-se que a implementação das medidas corretivas relacionadas a cada item são eficientes e eficazes.

PALAVRAS-CHAVE: Riscos físicos. Segurança no trabalho. Indústria de calçados. 


\section{INTRODUÇÃO}

A segurança do trabalho tem se tornado um dos pilares de sustentação da estrutura das empresas bem sucedidas. É evidente que as consequências negativas de um ambiente de trabalho insalubre ou inseguro, geram uma diminuição nos índices de produção, seja pelo afastamento do funcionário acidentado ou pelos impactos indiretos como na queda do rendimento da equipe de produção, como também pela diminuição da atenção e disposição dos trabalhadores em realizar um trabalho com excelência, pois os mesmos dedicarão parte de sua atenção e preocupação com os riscos dos quais estão expostos durante suas atividades sofrendo um maior desgaste físico do que se estivessem em ambiente salubre. Podemos citar outros malefícios para as empresas como os custos trabalhistas oriundos dos afastamentos, custos com novas contratações e tempo de treinamento devido ao aumento da rotatividade dos funcionários da empresa devido ao seu descontentamento com as condições de trabalho.

É importante encontrar modos de mapear os riscos existentes no ambiente fabril a fim de eliminá-los tornando o ambiente propício a um trabalho agradável. Neste trabalho iremos abordar a análise dos riscos físicos que são as diversas formas de energia a que possam estar expostos os trabalhadores, como: ruído, temperaturas extremas, vibrações, pressões anormais, radiações ionizante e não ionizantes. Para essa análise, iremos consultar principalmente as seguintes normas: A Norma Regulamentadora NR 09 que trata sobre riscos ambientais, suas etapas para avaliação e medidas de proteção contra as mesmas. A Norma Regulamentadora NR 15, que se caracteriza como critério legal, em seu Anexo no I estabelece os limites de tolerância para ruído contínuo ou intermitente, além da NBR 1052/1987, a qual fixa níveis de ruído compatíveis com o conforto acústico em ambientes diversos. e o anexo III da NR 15 que estabelece os limites de tolerância para exposição ao calor, e também Norma Regulamentadora NR 17 que visa estabelecer parâmetros que permitam a adaptação das condições de trabalho às características psicofisiológicas dos trabalhadores, proporcionando um máximo de conforto, segurança e desempenho eficiente.

O objeto do presente estudo foi uma indústria de pequeno porte do ramo calçadista que opera na cidade de Campina Grande, Paraíba. As operações da produção desta fábrica são organizadas por células que envolvem as atividades principais que vão do corte à costura, da montagem ao acabamento final do calçado. A fábrica funciona em regime de trabalho de oito horas diárias, com pausa de uma hora para almoço, disposto em um único turno, de segunda à sexta-feira. Para o desenvolvimento do presente estudo, foram realizadas visitas técnicas com o objetivo de identificar e avaliar os riscos físicos nos setores de produção e propor a implementação das correções necessárias para garantir as condições adequadas de trabalho, baseando-se em técnicas de gerenciamento de risco e nos requisitos das principais normas técnicas e regulamentadoras referenciadas.

No desenvolvimento do trabalho, buscou-se minimizar os riscos físicos a que os trabalhadores estavam expostos através da identificação de pontos críticos de exposição do operário nos distintos elementos que compõem o sistema produtivo da indústria, promovendo assim o êxito na segurança daqueles que estão envolvidos direta e indiretamente no processo de fabricação do produto. 
Neste trabalho foi utilizada a Análise Preliminar de Risco (APR) como ferramenta de gerenciamento de risco, que se mostrou uma técnica de identificação e análise de risco eficaz quando aplicada em falhas simples, que utiliza a probabilidade e a gravidade de um acidente ocasionado por um risco acontecer, ajudando na determinação dos problemas existentes a serem eliminados, facilitando a priorização dos problemas mais críticos em detrimento dos que possuem menores riscos. Além disso, um formulário de entrevista foi desenvolvido para obter melhores informações a respeito do ambiente fabril, prospectando a percepção do trabalhador a respeito de seu ambiente laboral.

\section{ETAPAS DO PROCESSO PRODUTIVO DO CALCPADO}

Em geral, o processo de fabricação do calçado pode ser dividido em seis etapas. A Figura 1 mostra o fluxograma que pode ser aplicado às etapas de produção de calçados na fábrica analisada no presente estudo. Tais processos podem variar conforme o tipo de calçado, material utilizado, ou por outras variáveis de influência (ABRAMEQ, 2010).

Observando a Figura 1, as duas primeiras etapas (Design e Modelagem) correspondem à idealização, ao desenvolvimento do conceito do produto e a adaptação do calçado projetado para manufatura.

Figura 1 - Etapas do processo de criação e fabricação de calçados

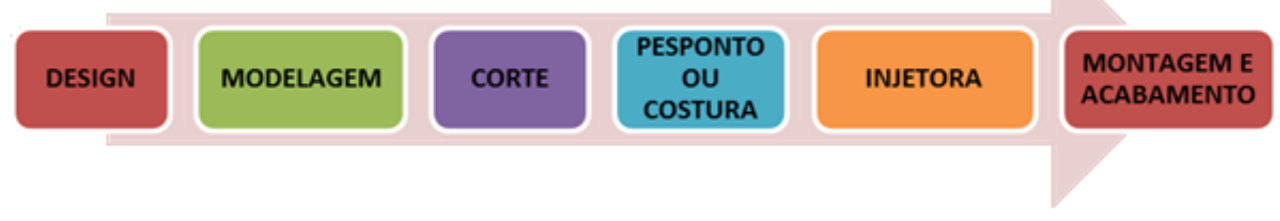

Fonte: Adaptado de ABRAMEQ (2010)

As etapas de corte, pesponto ou costura, injetora, montagem e acabamento, compreendem a fabricação do calçado e, ao mesmo tempo, acarretam os maiores riscos à saúde e segurança do trabalhador.

Durante o corte, da sola e outras partes que formam o calçado, são utilizados facas e balancins, que são máquinas para cortar materiais diversos como couros, termoplásticos, sintéticos, espumas, cortiça, plástico, borracha, EVA, papel, fibras têxteis e outros, os principais tipos de balancis empregados na fabricação de calçados no Brasil são o de braço móvel e o tipo ponte.

$\mathrm{Na}$ etapa de costura, as diferentes partes do cabedal, cortadas anteriormente, são costuradas, dobradas, picotadas ou coladas e, após, unidas. Dependendo do tipo de projeto, nesta fase podem ser utilizadas máquinas de costura de controle numérico. Embora os projetos de produtos mais padronizados possibilitem maior grau de automação, a implementação da automação nesta etapa, em muitos casos, é difícil e onerosa devido a muitos fatores, como diversidade de materiais empregados, diferentes rotas de costura, tipos de linha, além da grande variedade de modelos de produtos que variam sazonalmente. 
$\mathrm{Na}$ injetora e montagem ocorre a maior utilização de maquinário. O processo de injeção ocorre de forma direta, onde o material sintético (poliuretano, PU) é inserido em funil alimentador, em seguida esse material circula por um cilindro de plastificação e é então derramado sobre a fôrma do sapato a ser produzido de maneira semi automática, sendo o operador responsável pela movimentação do braço injetor e pelo comando de liberação da matéria prima, nessa fase também é feito o solado do calçado através de processo de injeção similar ao descrito anteriormente e em seguida a montagem é realizada de forma manual unindo os componentes de costura ao solado.

Durante o acabamento, o calçado é retirado da fôrma, passa na máquina de refilar e então pelos últimos detalhes: colocação de palmilha, etiquetas, enceramento, controle de qualidade, etc.

\section{ANÁLISE DE RISCO}

Uma das principais funções do setor de segurança do trabalho das empresas é controlar os riscos a que os trabalhadores estão submetidos. Para obter êxito nesta função é muito importante que o setor de segurança possua um sistema de gerenciamento de riscos para planejar, operar e controlar as atividades da empresa e seus respectivos riscos, mantendo-os dentro de valores tolerados.

A etapa de análise de riscos é uma etapa importante para o sucesso do sistema de gerenciamento de risco, ela compreende em identificar os perigos e avaliar os riscos associados que requer o uso de técnicas como a Análise Preliminar de Risco (APR), HAZOP, Análise dos Modos de Falha e Efeitos (AMFE), Análise por Árvores de Falha (AAF), Técnica de Incidente Crítico (TIC), entre outros.

A técnica de APR é definida por BARROS (2013, p. 76) como "uma metodologia indutiva estruturada para identificar os potenciais perigos decorrentes da instalação de novas unidades e sistemas ou da própria operação da planta que opera com materiais perigosos.". Nesta metodologia é importante que o analista examine os meios às quais as energias ou insumos do processo possam vir a ser disponibilizadas de formas descontroladas ou com perigos aos envolvidos na atividade, sendo analisados os métodos de detecção disponíveis (quantitativas ou qualitativas) e as consequências desses possíveis riscos aos colaboradores, à população circunvizinha e ao meio ambiente. Após as avaliações e a fase de medições dos riscos, deve ser feita a priorização dos mesmos e assim serão indicadas as medidas preventivas a fim de extinguir as causas ou mitigar as consequências dos cenários de possíveis acidentes identificados.

\section{RISCOS AMBIENTAIS}

De acordo com a Norma Regulamentadora 09, são considerados riscos ambientais os agentes físicos, biológicos e químicos. Eles são capazes de causar danos à saúde e à integridade física do trabalhador em função de sua natureza, concentração, intensidade, suscetibilidade e tempo de exposição.

Os riscos químicos são representados pelas substâncias químicas que se encontram nas formas líquida, sólida e gasosa. Quando absorvidas pelo 
organismo, podem produzir reações tóxicas e danos à saúde. As poeiras minerais, vegetais e alcalinas, fumos metálicos, nevoas, gases e vapores orgânicos e inorgânicos, são os agentes causadores desse tipo de risco.

Os riscos biológicos são aqueles causados por micro organismos como bactérias, fungos, vírus, bacilos e outros. São capazes de desencadear doenças devido à contaminação e pela própria natureza do trabalho.

Existem também outros agentes causadores de doenças do trabalho, afastamentos e desgastes físicos e mentais dos funcionários, que são os agentes ergonômicos e agentes de acidentes.

Os riscos ergonômicos são contrários às técnicas de ergonomia, que propõem que os ambientes de trabalho se adaptem ao homem, proporcionando bem-estar físico e psicológico. Os riscos ergonômicos estão ligados também a fatores externos (do ambiente) e internos (do plano emocional), em síntese, quando há disfunção entre o indivíduo e seu posto de trabalho.

A Norma Regulamentadora NR 17 vem em auxílio na luta contra os riscos ergonômicos, ao estabelecer parâmetros que ajudam a adatação das condições de trabalho às características psicofisiológicas dos colaboradores, com desempenho eficiente, segurança e o máximo de conforto. Essa norma orienta a todos no tocante a conforto ambiental, tratando desde o nível de ruído aceitável no trabalho, até as características dos assentos usados nos postos de trabalho, ou mesmo índice de temperatura, umidade relativa do ar e velocidade do ar nos locais de trabalho onde são executadas atividades que exijam solicitação intelectual e atenção constante.

Os riscos de acidentes ocorrem em função das condições físicas (do ambiente físico e do processo de trabalho) e tecnológicas, impróprias, capazes de provocar lesões à integridade física do trabalhador. São fortemente causadas por iluminações elétricas deficientes, máquinas sem proteção, arranjo físico inadequado, animais peçonhentos, EPI's sem certificação, dentre outros.

\section{CONFORTO TÉRMICO}

O corpo humano é homeotérmico, isto é, mantém a temperatura corporal interna relativamente constante, desde que não ultrapasse certos limites, independente da temperatura ambiente. Portanto, o conforto térmico está relacionado ao equilíbrio térmico do corpo humano, que é condição essencial para a saúde, segurança e produtividade dos trabalhadores, e mantido, por um sistema orgânico, chamado de termorregulador (RUAS, 2001).

O superaquecimento gera cansaço e sonolência, redução do desempenho físico e aumento dos erros. Ao contrário, condições de bastante frio reduz o estado de alerta e concentração, particularmente nas atividades mentais. Logo a manutenção do clima confortável é essencial para o bem estar, desempenho e eficiência máxima (KROEMER \& GRANDJEAN, 2005).

A sobrecarga térmica no organismo humano é resultante de duas parcelas de carga térmica: uma carga externa (ambiental) e outra interna (metabólica). A carga externa é resultante das trocas térmicas com o ambiente e a carga metabólica é resultante da atividade física que exerce. 
Os cálculos analíticos do conforto térmico são influenciados por variáveis ambientais e pessoais ou subjetivas, por não dependerem do ambiente: temperatura do ar (으); temperatura radiante média, trm, (으); velocidade do ar, Var, $(\mathrm{m} / \mathrm{s})$; pressão parcial do vapor de água no ar ambiente, pa, (kPa); atividade desempenhada, $\mathrm{M},(\mathrm{W} / \mathrm{m} 2)$; isolamento térmico das roupas utilizadas, Icl, (clo).

A análise do conforto térmico pode ser realizada através de diversos métodos. Para haver conforto térmico numa determinada atividade física o corpo deve estar em equilíbrio térmico, com certa temperatura média de pele e perdendo certa quantidade de calor por evaporação do suor. Então, a combinação das variáveis pessoais com as variáveis ambientais pode ser equacionada para se obter uma medida do conforto térmico. Um critério bastante adotado é o do Voto Médio Estimado (VME) de um grupo de pessoas, dado na norma ISO 7730/05 que se baseia na relação entre a resposta fisiológica do sistema termorregulador humano e a sensação térmica das pessoas estabelecidas pela escala da Tabela 1.

Tabela 1 - Escala de Sensação Térmica do VME

$\begin{array}{cccccccc}\text { VME } & -3 & -2 & -1 & 0 & 1 & 2 & 3 \\ \text { Sensação } & \text { Muito } & & \text { Ligeira- } & & \text { Ligeira- } & & \text { Muito } \\ \text { Térmica } & \text { Frio } & \text { Frio } & \begin{array}{c}\text { mente } \\ \text { frio }\end{array} & \text { Neutro } & \begin{array}{c}\text { mente } \\ \text { quente }\end{array} & \text { Quente } & \begin{array}{c}\text { Muente } \\ \end{array} \\ & & & & \text { quente }\end{array}$

Fonte: Adaptado de ABRAMEQ (2010)

Como foi provado por experiências é impossível obter em um ambiente, combinação das variáveis de conforto que satisfaça plenamente todos os integrantes de um grande grupo; sempre existirão insatisfeitos. Uma forma mais prática é relacionar o VME com a porcentagem de insatisfeitos. $O$ resultado pode ser expresso em termos da curva da Figura 2, que mostra a porcentagem de insatisfeitos para cada valor de VME (SILVA, 2007).

Figura 2 - Gráfico do PPD em função do PMV

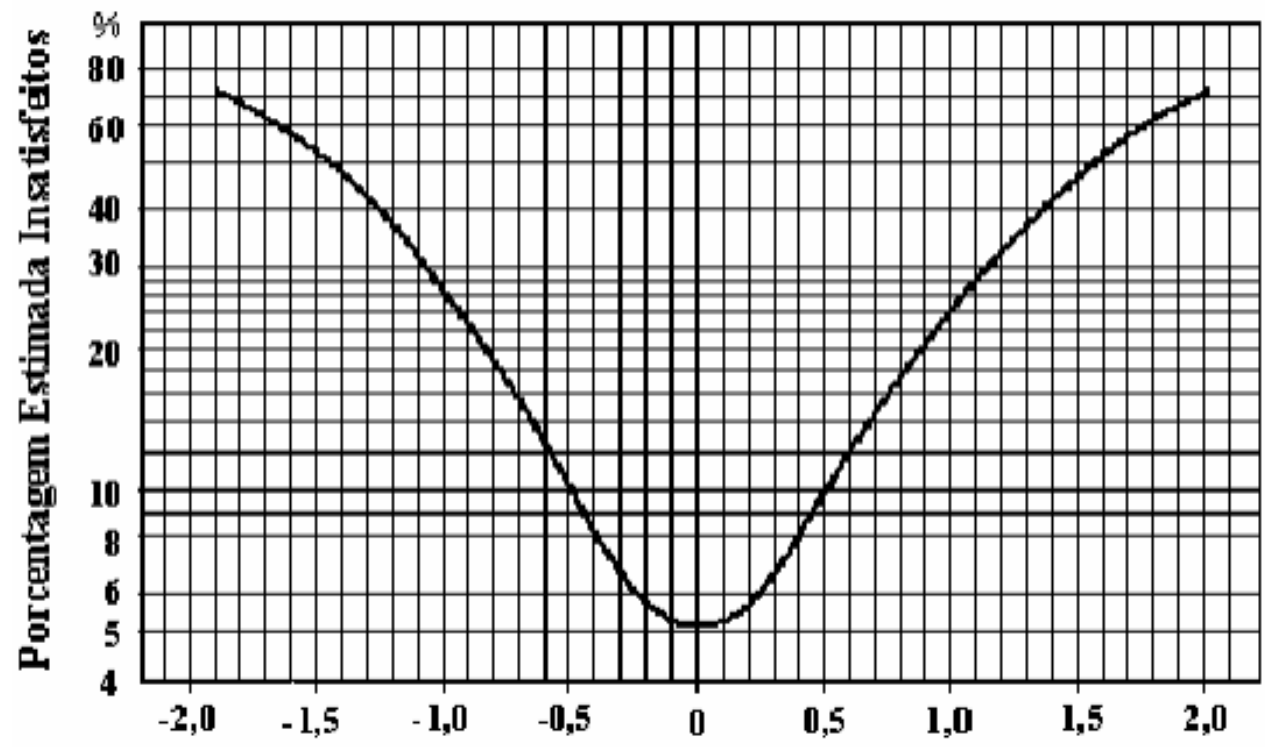

Fonte: SILVA, 2007. 
De acordo com a NR 17 (Norma Regulamentadora 17), item 4.2, a zona de conforto é delimitada entre as temperaturas efetivas de 20 a $23^{\circ} \mathrm{C}$, com umidade relativa não inferior a $40 \%$, com velocidade do ar moderada, da ordem máxima de $0,75 \mathrm{~m} / \mathrm{s}$. A ventilação é um aspecto importante para o conforto térmico. Em ambiente com uma temperatura elevada é aliviante sentir uma leve brisa junto à pele, ela ajuda a remover por convecção o calor gerado pelo corpo.

A NR 15 avalia a exposição ao calor através do índice IBUTG (Índice de Bulbo Úmido e Termômetro de Globo). O IBUTG leva em considerações, variáveis ambientais relacionando-as com o metabolismo do indivíduo no seu posto de trabalho e a sua execução, conforme mostrado na Tabela 2.

Se o trabalho é realizado em mais de um ponto, fato ocorrido na maioria das

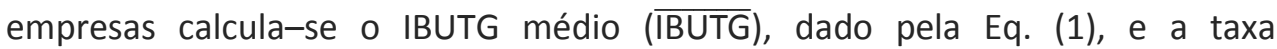
metabólica média ( ), dada pela Eq. (2). Portanto, têm-se:

$$
\overline{\mathrm{IBTUG}}=\frac{\left(\mathrm{IBUTG}_{\mathrm{t}} * \mathrm{~T}_{\mathrm{t}}\right)+\left(\mathrm{IBUTG}_{\mathrm{d}} * \mathrm{~T}_{\mathrm{d}}\right)}{60}
$$

Onde $\overline{\mathrm{IBUTG}}$ é o valor IBUTG médio ponderado para uma hora, IBUTGt é o valor do IBUTG no local de trabalho, IBUTGd é o valor do IBUTG no local de descanso. Tt (em minutos) é a soma dos tempos em que se permanece no local de trabalho e $\mathrm{Td}$ (em minutos) é a soma dos tempos em que se permanece no local de descanso que devem ser tomados no período mais desfavorável do ciclo de trabalho. Em tempo corrido têm-se $\mathrm{Tt}+\mathrm{Td}=60 \mathrm{~min}$.

Tabela 2 - Regime de trabalho intermitente por tipo de atividade

\begin{tabular}{|c|c|c|c|}
\hline $\begin{array}{l}\text { Regime de trabalho intermitente } \\
\text { com descanso no próprio local de } \\
\text { trabalho (por hora) }\end{array}$ & Leve & Moderada & Pesada \\
\hline Trabalho contínuo & até 30,0 & até 26,7 & até 25,0 \\
\hline $\begin{array}{l}45 \mathrm{~min} \text {. de trabalho } \\
15 \mathrm{~min} . \text { de descanso }\end{array}$ & 30,1 a 30,5 & 26,8 a 28,0 & 25,1 a 27,9 \\
\hline $\begin{array}{l}30 \mathrm{~min} \text {. de trabalho } \\
30 \mathrm{~min} \text {. de descanso }\end{array}$ & 30,7 a 31,4 & 28,1 a 29,4 & 26,0 a 27,9 \\
\hline $\begin{array}{l}15 \text { min. de trabalho } \\
45 \mathrm{~min} . \text { de descanso }\end{array}$ & 31,5 a 32,2 & 29,5 a 31,1 & 28,0 a 30,0 \\
\hline $\begin{array}{l}\text { Não é permitido o trabalho, sem } \\
\text { adoção de medidas adequadas de } \\
\text { controle. }\end{array}$ & acima de 32,2 & $\begin{array}{l}\text { acima de } \\
31,1\end{array}$ & acima de 30,0 \\
\hline
\end{tabular}

Fonte: Norma Regulamentadora NR15

O IBUTG deve ser relacionado ainda ao tipo de ambiente, de acordo com as Eq. (3) e (4). Então, para ambientes internos ou externos sem carga solar, tem-se a Eq. (3).

IBUTG $=0,7 \mathrm{tbn}+0,3 \mathrm{tg}$

A Eq. (4) relaciona a ambientes externos com carga solar.

IBUTG $=0,7 \mathrm{tbn}+0,3 \mathrm{tbs}+0,2 \mathrm{tg}$ 
Sendo tbn a temperatura de bulbo úmido natural, tg é a temperatura de globo e tbs a temperatura de bulbo seco.

\section{RUÍDO}

O som resulta de um movimento vibratório que produz uma modificação da pressão em meios elásticos, propagando-se em forma de ondas ou oscilações mecânicas, longitudinais e tridimensionais. As características fundamentais elencadas ao fenômeno são: a frequência, que se refere à altura do som; a amplitude, relacionada à intensidade sonora; e o timbre, que diferencia, por exemplo, a mesma nota musical emitida por instrumentos diferentes, através de diversas frequências harmônicas de que se compõem um determinado som complexo (MEDEIROS, 1999).

O alcance da audição humana, para um ouvido jovem e saudável, se estende de aproximadamente $20 \mathrm{~Hz}$ até $20.000 \mathrm{~Hz}$ de frequência e de aproximadamente $0 \mathrm{~dB}$ até $120 \mathrm{~dB}$ de intensidade. Quando o som não é desejado ou é incômodo ou possui uma combinação não harmoniosa, se diz que o mesmo se transformou em ruído ou barulho.

Existem alguns fatores responsáveis por transformar um som agradável em um ruído irritante e desagradável. São eles: distância da fonte geradora de ruído, tipos de ruídos, frequência/intensidade, susceptibilidade individual e a duração da exposição. Este último determina a maior probabilidade do trabalhador desenvolver ou agravar uma perda auditiva se estiver durante longo período de tempo exposto a ruído contínuo.

O ruído contínuo é o que permanece estável com variações máximas de 3 a 5 $\mathrm{dB}(\mathrm{A})$ durante um longo período. O ruído intermitente é um ruído com variações maiores ou menores de intensidade em períodos muito curtos (NHO 01, 2001).

A avaliação da exposição de um trabalhador ao ruído contínuo ou intermitente por meio do nível de exposição deve ser realizada utilizando medidores integradores de uso pessoal. O Nível de Exposição (NE) é o nível médio representativo da exposição diária do operador avaliado.

Para fins de comparação com o limite de exposição, deve-se determinar o Nível de Exposição Normalizado (NEN), este corresponde ao NE convertido para jornada padrão de oito horas diárias. Sempre que o NEN for superior a $85 \mathrm{~dB}(\mathrm{~A})$, o limite de exposição estará ultrapassado e exigirá adoção imediata de medidas de controle (NHO 01, 2001).

Se o NEN estiver entre 82 e $85 \mathrm{~dB}(\mathrm{~A})$, a exposição deve ser considerada acima do nível de ação, devendo ser adotadas medidas preventivas (NHO 01, 2001).

A Tabela 3 é reproduzida do Anexo no da NR 15 que mostra o limite de tolerância para ruído contínuo ou intermitente. 
Tabela 2 - Limites de tolerância à exposição ao ruído (contínuo ou intermitente)

\begin{tabular}{c|c}
\hline NíVEL DE RUÍDO dB (A) & MÁXIMA EXPOSIC̃̃̃O DIÁRIA PERMISSÍVEL \\
\hline 85 & 8 horas \\
86 & 7 horas \\
87 & 6 horas \\
88 & 5 horas \\
89 & 4 horas e 30 minutos \\
90 & 4 horas \\
91 & 3 horas e 30 minutos \\
92 & 3 horas \\
93 & 2 horas e 40 minutos \\
94 & 2 horas e 15 minutos \\
95 & 2 horas \\
96 & 1 hora e 45 minutos \\
98 & 1 hora e 15 minutos \\
100 & 1 hora \\
102 & 45 minutos \\
104 & 35 minutos \\
105 & 30 minutos \\
106 & 25 minutos \\
108 & 20 minutos \\
110 & 15 minutos \\
112 & 10 minutos \\
114 & 8 minutos \\
115 & 7 minutos \\
\hline
\end{tabular}

Fonte: Norma Regulamentadora NR15

A interpretação da dose diária de exposição ao ruído consiste em: sempre que a dose diária for superior a 100\%, o limite de exposição estará excedido e exigirá a adoção imediata de medidas de controle. Se a dose diária estiver entre $50 \%$ e $100 \%$ a exposição deve ser considerada acima do nível de ação, devendo ser adotadas medidas preventivas de forma a minimizar a probabilidade de que o alto nível de ruído cause alterações na audição do trabalhador e evitar que o limite de exposição seja ultrapassado.

\section{MATERIAIS E MÉTODOS}

A metodologia de Análise Prelimar de Risco (APR) foi desenvolvida a partir da observação detalhada da incidência de riscos e insegurança no trabalho utilizando a tabela de análise de riscos (Tabela 4), e aplicação de entrevistas aos funcionários servindo como fonte importante de informações a respeito da probabilidade e gravidade de riscos. A fim de identificar divergências entre o trabalho preescrito e o realizado pelo profissional no posto de trabalho, assim como os fatores atenuantes dos riscos ocupacionais, foi realizado um estudo através de observações (analise qualitativa) com o objetivo de preencher a Tabela 4 a seguir. 


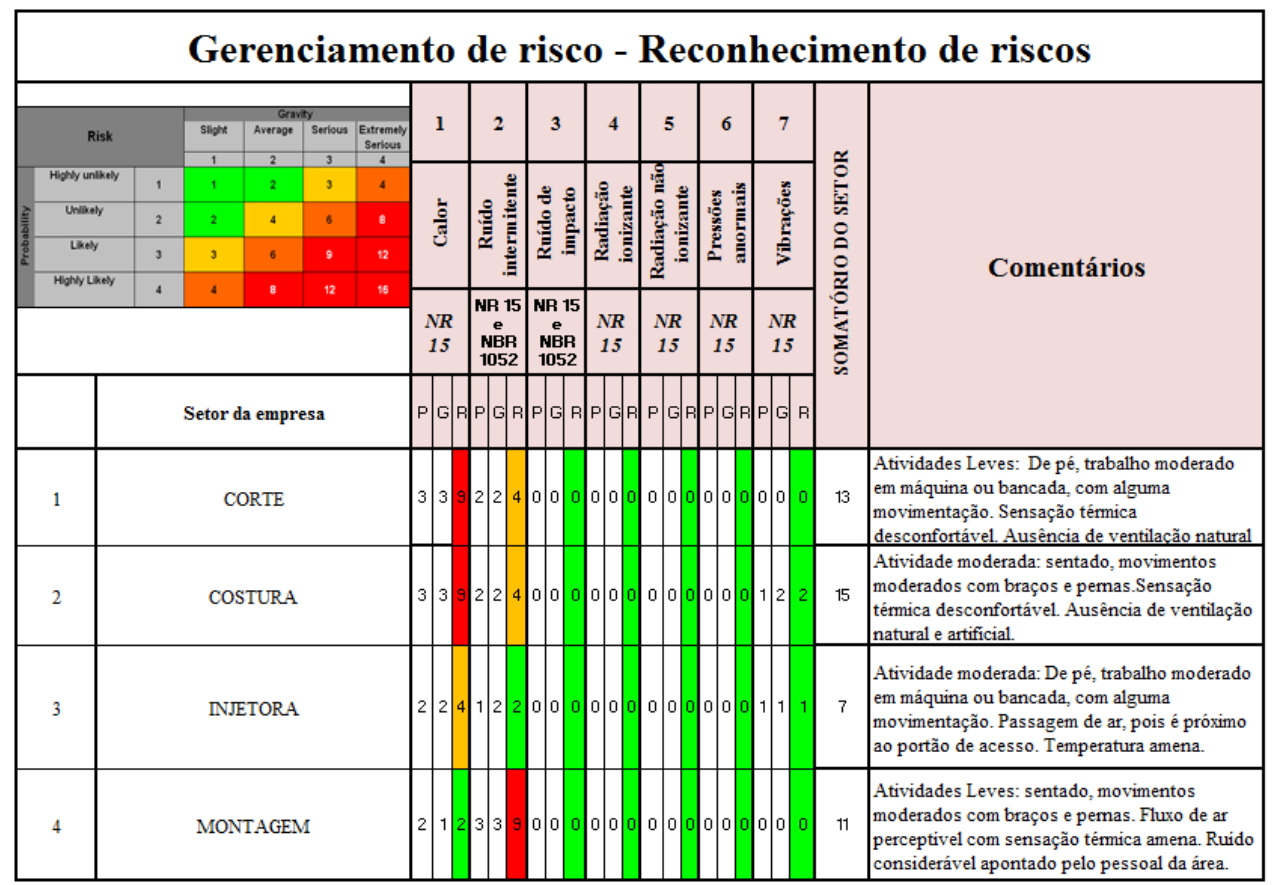

Fonte: Os autores

Sendo obtido o risco (letra "R" na tabela) através da matriz gravidade (letra " $G$ " na tabela) versus probabilidade (letra " $P$ " na tabela), em que a gravidade é obtida através da avaliação das possíveis afastamentos ou seriedade do problema ocasionados por aquele agente físico, variando de "Slight" (gravidade leve ou sem afastamento com perda de tempo) até "Extremely Serious" (acidente com gravidade alta ou com risco de morte), existindo também as opções "Average", considerada como acidente ou afastamento com perda de tempo menor que quinze dias e "Serious" como acidente grave ou afastamento com perda de tempo maior que quinze dias. Para obter a probabilidade de o risco gerar consequências nocivas, foram consideradas quatro opções que vai de "Higly Unlikely" onde não há relatos de acidentes ou afastamentos, em seguida a opção "Unlikely" para mais de uma reclamação ou comunicado dos funcionários nos últimos doze meses, em "Likely" para um afastamento graças ao risco analisado nos últimos doze meses e "Highly Likely" para mais de um afastamento nos últimos doze meses.

Foi utilizado um questionário com perguntas respondidas pelos funcionários (apendice) com o intuito de coletar informações sobre a situação percebida por estes no seu posto de trabalho e através da análise prévia das normas da legislação brasileira relacionadas aos riscos físicos foi feita o preenchimento uma etapa inicial de reconhecimento e preenchimento da tabela mostrada acima (Tabela 04).

No diagrama APR, foi visto que os setores mais críticos eram o de corte e costura, sendo esses o com a maior quantidade de problemas observados assim como também questionados pelos colaboradores em relação a desconfortos durante o desenvolvimento de suas atividades. 
Os resultados obtidos serviram de base para a formulação do diagnóstico verificado na empresa e a partir deste, foram propostas ações para melhoria das condições de trabalhos dos locais analisados.

\section{MENSURAÇÕES DO CONFORTO TÉRMICO}

Ao todo, foram realizadas medições, durante duas semanas consecutivas, englobando seis visitas em dias alternados. Além disso, foram aplicados questionários específicos de avaliação térmica. Nos quesitos "Fatores que influenciam na sensação de frio no inverno" e "Fatores que influenciam na sensação de calor no verão", os entrevistados poderiam marcar mais de uma opção. Nos outros quesitos era possível marcar apenas uma opção.

O levantamento das variáveis ambientais deve ser planejado com especial atenção às peculiaridades de cada local e das atividades lá desenvolvidas.

A umidade relativa normalmente é igual em todo ambiente, e pode ser medida em qualquer ponto da área ocupada. As demais variáveis foram medidas múltiplos quadrados iguais de 2 a $4 \mathrm{~m}$ de lado e a realização das medições no centro desses quadrados, de forma que se consiga um levantamento completo das variáveis ambientais em toda a área ocupada.

Utilizou-se o Medidor Eletrônico Termômetro de Globo modelo TGD-200 e o Termo-higro-anemômetro Digital Portátil modelo THAR-185, ambos do fabricante Instrutherm.

A temperatura do ar foi medida com termômetro de mercúrio com escala mínima de 0 a $50^{\circ} \mathrm{C}$, precisão mínima de $\pm 0,10 \mathrm{C}$, exatidão de $\pm 0,5^{\circ} \mathrm{C}$ e com tempo de resposta adequado ao número de medidas executadas.

A velocidade do ar foi medida com um termo anemômetro de sensor unidirecional com capacidade para medir velocidades da ordem de $0,05 \mathrm{~m} / \mathrm{s}$, com escala mínima de 0 a $10 \mathrm{~m} / \mathrm{s}$, exatidão de $0,05 \mathrm{~m} / \mathrm{s}$ e tempo de resposta da ordem de 1 a 10 segundos.. Para a obtenção do valor médio da velocidade no ponto estabelecido, foram feitas várias medidas a cada 15 segundos durante um período de 3 a 5 minutos, considerando as flutuações de velocidade normalmente existentes.

\section{MENSURAÇ̃̃ES DOS NÍVEIS DE EXPOSIC̣ÃO AO RUIDO}

O ruído identificado é do tipo contínuo e o Nível de Exposição (NE) para cada setor da fábrica foi calculado conforme o procedimento a seguir.

A avaliação do conforto acústico foi feita pela verificação de níveis emitidos em torno da máquina e próximos à região da cabeça do indivíduo, para um ritmo de trabalho de 8 horas. Quando for o caso, uma verificação da necessidade de medidas coletivas para a atenuação do ruído emitido na fonte deve ser realizada.

Assim, a metodologia adotada foi a mensuração do ruído realizado próximo ao ouvido do trabalhador que manipulava a máquina/equipamento, por meio de um dosimetro da marca Instrutherm, modelo DEC-5010. Utilizou-se também um calibrador acústico do mesmo fabricante modelo CAL - 3000, para aferição do decibelímetro antes e a após cada medição. Ambos os equipamentos possuíam 
certificados de calibração. 0 tempo de medição foi de 2 horas no turno matutino e 2 horas no turno vespertino.

\section{RESULTADOS E DISCUSSÃO}

\section{RESUMO DAS CONDIÇÕES INSALUBRE AVALIADAS}

O Quadro 1 foi sumarizada para os valores das operações e atividades insalubres identificadas através de medições in loco nos tópicos anteriores. Percebe-se pelo quadro que todos os setores precisam de adequações. Isto pode ser comprovado quando são comparados estes valores obtidos com as recomendações da NR-15 e NR 17.

Quadro 1 - Medidas termofísicas dos diversos setores da fábrica de calçados

\begin{tabular}{|c|c|c|c|c|c|c|}
\hline Setor & Atividade & $\begin{array}{c}\boldsymbol{V}_{\mathrm{ar}} \\
{[\mathrm{m} / \mathrm{s}]}\end{array}$ & $\begin{array}{l}\text { IBUTG } \\
{\left[{ }^{\circ} \mathrm{C}\right]}\end{array}$ & $\begin{array}{l}\text { Ruído } \\
\text { [dB] }\end{array}$ & $\begin{array}{c}\text { Umidade } \\
\text { relativa } \\
{[\%]}\end{array}$ & $\begin{array}{c}\text { NR } 15 \\
\text { Anexo } 1 \text { e } 3 \\
\text { Quadro } 1 \text { e } 3\end{array}$ \\
\hline Pesponto & Leve & 0,0 & 29,7 & 82,6 & 68 & $\begin{array}{l}45 \mathrm{~min} \text {. de trabalho } \\
15 \mathrm{~min} \text {. de descanso }\end{array}$ \\
\hline Corte & Moderada & 0,0 & 29,8 & 82,7 & 68 & $\begin{array}{l}15 \mathrm{~min} \text {. de trabalho } \\
45 \mathrm{~min} \text {. de descanso }\end{array}$ \\
\hline $\begin{array}{l}\text { Injetora } \\
\text { de Pu }\end{array}$ & Moderada & 0,3 & 26,9 & 77,8 & 55 & $\begin{array}{l}45 \mathrm{~min} \text {. de trabalho } \\
15 \mathrm{~min} \text {. de descanso }\end{array}$ \\
\hline $\begin{array}{c}\text { Montage } \\
\mathrm{m}\end{array}$ & Leve & 0,4 & 26,6 & 89,3 & 56 & $\begin{array}{l}\text { 04hs30min, máximo } \\
\text { de exposição ao ruído }\end{array}$ \\
\hline
\end{tabular}

Fonte: Os autores

\section{ADEQUAÇÕES REALIZADAS}

A fim de mitigar o problema de temperatura e falta de renovação do ar verificados no quadro 01, foram instalados ventiladores e 7 (sete) exaustores industriais no setor. As modificações estão apresentadas nas Figuras abaixo.

Figura 3: Instalação de ventiladores nos setores de corte e pesponte

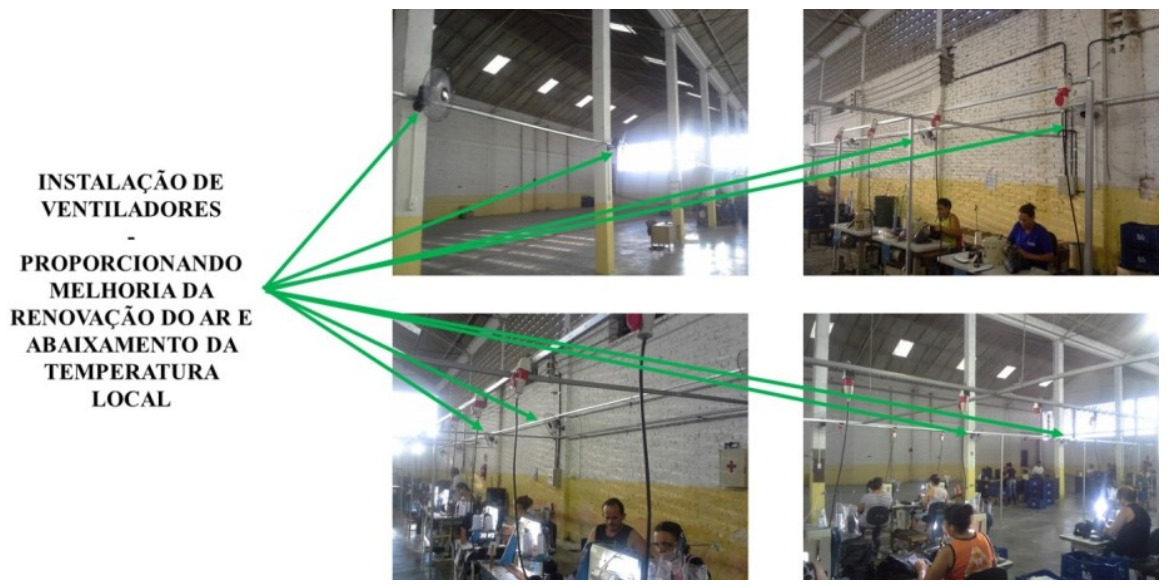

Fonte: Os autores 
Figura 4 - Instalação de exaustores industriais no setor de corte

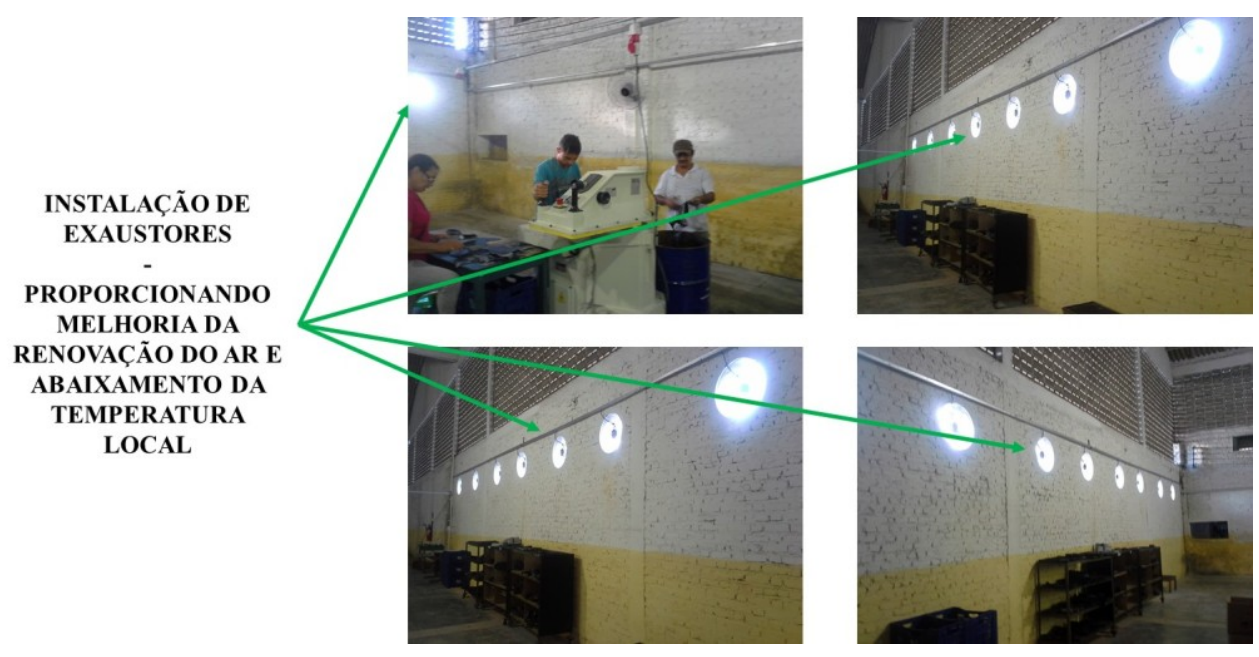

Fonte: Os autores

As modificações proporcionaram diminuição da temperatura do setor, diluição dos gases e aumento da velocidade do ar. O Quadro 2 apresenta os novos valores de velocidade do ar e IBUTG do setor de corte e pesponto.

Quadro 2 - Novas medidas termofísicas dos diversos setores após implementação das modificações propostas

\begin{tabular}{|c|c|c|c|c|c|c|}
\hline Setor & Atividade & $\begin{array}{c}\boldsymbol{V}_{\mathrm{ar}} \\
{[\mathrm{m} / \mathrm{s}]}\end{array}$ & $\begin{array}{l}\text { IBUTG } \\
{\left[{ }^{\circ} \mathrm{C}\right]}\end{array}$ & $\begin{array}{l}\text { Ruído } \\
\text { [dB] }\end{array}$ & $\begin{array}{c}\text { Umidade } \\
\text { relativa } \\
{[\%]}\end{array}$ & $\begin{array}{c}\text { NR } 15 \\
\text { Anexo } 1 \text { e } 3 \\
\text { Quadro } 1 \text { e } 3\end{array}$ \\
\hline Pesponto & Leve & 0,6 & 27,5 & 82,6 & 68 & Trabalho contínuo \\
\hline Corte & Moderada & 0,6 & 27,2 & 82,7 & 68 & $\begin{array}{l}45 \mathrm{~min} \text {. de trabalho } \\
15 \mathrm{~min} \text {. de descanso }\end{array}$ \\
\hline $\begin{array}{c}\text { Injetora de } \\
\mathrm{Pu}\end{array}$ & Moderada & 0,3 & 26,9 & 77,8 & 55 & $\begin{array}{l}45 \mathrm{~min} \text {. de trabalho } \\
15 \mathrm{~min} \text {. de descanso }\end{array}$ \\
\hline Montagem & Leve & 0,4 & 26,6 & 89,3 & 56 & $\begin{array}{l}\text { 04hs30min, máximo } \\
\text { de exposição ao ruído }\end{array}$ \\
\hline
\end{tabular}

Fonte: Os autores

No setor de montagem o nível de ruído, se encontrava acima do limite de tolerância de $85 \mathrm{~dB}$ estipulados na NR 15 (Anexo I) para uma carga horária de 8 horas de trabalhos diários, então foram verificadas as fontes geradoras de ruídos, em que foi percebida a existência de grande quantidade de máquinas como máquinas de refilar, máquinas de montar bico e lixadeiras, foram então analisadas as opções de medidas de controle do ruído na fonte, na trajetória e no homem, sendo esta última opção escolhida pela empresa por ser a alternativa mais viável, atendendo de forma consistente a atenuação de ruído através da aplicação do equipamento de proteção individual, o protetor auricular tipo plug com nível de Redução de Ruído de $17 \mathrm{~dB}$, mantendo assim os níveis de ruído dentro do permitido e aceitável. 
Após os levantamentos iniciais, feitos a partir de avaliações qualitativa e aplicando-se um questionário aos funcionários para identificação dos principais desconfortos, foi então realizada uma análise quantitativa aprofundada, com o auxilio de equipamentos técnicos da área, em que se constatou, com as medições realizadas e de acordo com a literatura técnica que envolve o assunto, a existência da necessidade de modificações e ajustes dos fatores que contribuem para uma melhoria da qualidade e das condições de trabalho.

Quanto aos níveis de ruídos mais elevados registrados em algumas máquinas, foram indicados à empresa a realização do revestimento com espumas ou combinando espumas de poliuretano com franjas de EVA que são materiais absorventes e desgastam as ondas sonoras, diminuindo sua energia de propagação na origem, e enquanto essas medidas coletivas não forem implantadas, serão fornecidos e utilizados continuamente protetores auriculares do tipo plug, para que as atividades desempenhadas no ambiente com maior índice de ruído permaneça dentro dos limites indicados para ambientes de trabalhos salubres.

As temperaturas elevadas medidas na indústria e a falta de ventilação natural dos setores analisados, resultaram em ações imediatas realizadas a fim de reduzir as temperaturas ambientais por meio de uma melhor ventilação do setor e através da instalação de exaustores foram obtidas reduções de até 2,90 IBUTG melhorando assim as condições de trabalho com aumento na produtividade dos funcionários, além das diminuições do tempo das pausas de descanso obrigatórias (na área de corte houve aumento de 30 minutos de trabalho por hora com a inserção dos exaustores e aumento de temperatura, na área de pesponto havendo um ganho de 15 minutos de trabalho por hora, eliminando os 15 minutos de pausa obrigatórios). Essa ação mostrou de forma inequívoca que é possível haver investimentos em segurança do trabalho que gerem lucros e comprovam que a área de segurança do trabalho anda junto com a eficiência e o aumento da produtividade. 


\title{
Management of physical risks in the environment of a footwear industry
}

\begin{abstract}
Industrial accidents and occupational health problems are constant in various industries. However, these side issues can be mitigated or extinguished when you have a careful design to eliminate the potential physical, chemical and biological agents that carry risks to the integrity and health of workers. This study aims to assess the physical risks and propose appropriate solutions in the workplace of a micro-footwear industry in the city of Campina Grande-PB. To develop such, it had as basis the current regulatory standards. The methodology consisted of field research and analysis of the exposure of workers to the eminently physical risks. The suggested solutions ensure compliance with regulatory requirements, which tendencies to reduce audible noise, getting the minimum thermal comfort, increased internal luminance and the safe operation of machinery. It is concluded that the implementation of the corrective measures relating to each item are efficient and effective.
\end{abstract}

KEYWORDS: Physical risks. Risk analysis. Safety at work. Shoe industry. 


\section{REFERÊNCIAS}

ABRAMEQ / SEBRAE-RS. Cartilha de Segurança em Máquinas e Equipamentos para Calçados - Requisitos Mínimos de Segurança. ABRAMEQ: Novo Hamburgo RS, 2010.

BARROS, S.S. Análise de riscos. Caderno elaborado pelo Instituto Federal do Paraná para a rede e-Tec Brasil. Instituto Federal do Paraná - PR, 2013.

ISO (INTERNATIONAL ORGANIZATION FOR STANDARDIZATION). 7730:

Ergonomics of the thermal environment - Analytical determination and interpretation of thermal comfort using calculation of the PMV and PPD indices and local thermal comfort criteria.

KROEMER, K. H. E.; GRANDJEAN, E. Manual de ergonomia: adaptando o trabalho ao homem. 5.ed. Porto Alegre: Bookman, 2005.

MEDEIROS, L.N. Ruído: efeitos extra-auditivos no corpo humano. Monografia (Especialização em Audiologia Clínica), Centro de Especialização em Fonoaudiologia Clínica Audiologia Clínica: Porto Alegre - RS, 1999.

NORMA DE HIGIENE OCUPACIONAL 01 - FUNDACENTRO. NHO 01 - Avaliação da exposição ocupacional ao ruído. 2001

NORMA REGULAMENTADORA - MINISTÉRIO DO TRABALHO E EMPREGO. NR 15 Atividades e Operações Insalubres. 2009.

NORMA REGULAMENTADORA - MINISTÉRIO DO TRABALHO E EMPREGO. NR 17 . Ergonomia. 2009.

RUAS, A. C. Avaliação do conforto térmico - contribuição à aplicação prática das normas internacionais. Dissertação (Mestrado em Eng. Civil). Unicamp: Campinas - SP, 2001.

SILVA, N. R. Avaliação do conforto térmico. Monografia (Trabalho de Conclusão de Curso em Engenheira de Segurança do Trabalho). Universidade Santa Cecília: Santos - SP, 2008. 


\section{QUESTIONÁRIO - LAUDO ERGONÔMICO}

SETOR:

CORTE

PESPONTO

$\left.\begin{array}{l}{[} \\ {[}\end{array}\right]$

MONTAGEM

SEXO:

IDADE:

[. $] \mathrm{M}$

[ ] F

MENOR QUE 18 [ ] ]

$18 \mathrm{~A} 25$ [ $\mathrm{m}]$

26 A 35 [ ]

MAIOR QUE 55 [ ]

NIIVLL DE BEM ESTAR

BEM

STRESS BAIXO

STRESS MEDIO [

STRESS ALTO $\llbracket$

MAU

$36 \mathrm{~A} 45[\mathrm{~B}]$

\section{CLASSIFICAC̣̃̃O DO POSTO DE TRABALHO}

$\mathrm{BOM}[\ldots]$

RUIM[ ]

CONDIC̣ÕES FÍSICAS

QUENTE

BARULHENTO

VENTILADO

SUJO

AMENO

SILENCIOSO

ABAFADO

LIMPO

\section{ESCLARECIMENTOS}

NÄO E PRECISO SE IDENTIFICAR:

ESTA PESQUISA COMPÖE AS ATIVIDADES EXIGIDAS NO LAUDO ERGONÖMCO PARA O MTE;

AS INFORMAÇÖES AQUI PRESTADAS SÄO A VERIFICACÄO DA VERDADE.

RESPONDER SEMPRE COM A VERDADE, POIS AS INFORMAÇÖES AQUI PRESTADAS PODEM ACARRETAR EM MELHORIAS EM SEU POSTO DE TRABALHO

Recebido: 12 abr 2017

Aprovado: 20 mar 2018

DOI: 10.3895/gi.v14n1.5749

Como citar:

ALBUQUERQUE, D. F. F.; NÓBREGA, J. A.; MELO, R. H. F.; PIRES, C. A. Gerenciamento de riscos físicos em ambiente fabril de calçados. R. Gest. Industr., Ponta Grossa, v. 14, n. 4, p. 19-35, jan./mar. 2018

Disponível em: <https://periodicos.utfpr.edu.br/rgi>. Acesso em: XXX

Correspondência:

Daniel Ferreira Fernandes de Albuquerque

Rua Artur Enedino dos Anjos, 311, Apto 103, Altiplano, João Pessoa, PB, Brasil

Direito autoral: Este artigo está licenciado sob os termos da Licença Creative Commons-Atribuição 4.0

Internacional.

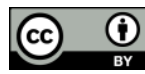

